\title{
Meckel Diverticulum Neuroendocrine Tumor G1
}

National Cancer Institute

\section{Source}

National Cancer Institute. Meckel Diverticulum Neuroendocrine Tumor G1. NCI

Thesaurus. Code C6424.

A well differentiated, low grade neuroendocrine tumor (carcinoid tumor) that arises in a Meckel diverticulum. 